\title{
Skin-Effect Self-Heating in Air-Suspended RF MEMS Transmission-Line Structures
}

\author{
Linda L. W. Chow, Student Member, IEEE, Zhongde Wang, Member, IEEE, Brian D. Jensen, \\ Kazuhiro Saitou, Member, IEEE, Member, ASME, John L. Volakis, Fellow, IEEE, and \\ Katsuo Kurabayashi, Member, IEEE
}

\begin{abstract}
Air-suspension of transmission-line structures using microelectromechanical systems (MEMS) technology provides the effective means to suppress substrate losses for radio-frequency (RF) signals. However, heating of these lines augmented by skin effects can be a major concern for RF MEMS reliability. To understand this phenomenon, a thermal energy transport model is developed in a simple analytical form. The model accounts for skin effects that cause Joule heating to be localized near the surface of the RF transmission line. Here, the model is validated through experimental data by measuring the temperature rise in an air-suspended MEMS coplanar waveguide (CPW). For this measurement, a new experimental methodology is also developed allowing direct current (dc) electrical resistance thermometry to be adopted in an RF setup. The modeling and experimental work presented in this paper allow us to provide design rules for preventing thermal and structural failures unique to the RF operation of suspended MEMS transmission-line components. For example, increasing the thickness from 1 to $3 \mu \mathrm{m}$ for a typical transmission line design enhances power handling from 5 to $125 \mathrm{~W}$ at $20 \mathrm{GHz}, 3.3$ to $80 \mathrm{~W}$ at $50 \mathrm{GHz}$, and 2.3 to $56 \mathrm{~W}$ at $100 \mathrm{GHz}$ (a 25 -fold increase in RF power handling).

[1737]
\end{abstract}

Index Terms-Coplanar waveguides (CPWs), failure analysis, microelectromechanical devices, skin effect, transmission lines.

\section{INTRODUCTION}

$\mathbf{L}$ OW-LOSS and low-dispersion transmission-line structures are critical components in radio-frequency (RF)/microwave circuit design. Air-suspended transmission-line structures, with their suspension above the commonly used complementary metal-oxide-semiconductor (CMOS) or GaAs substrates, can serve as fundamental building blocks to achieve low-loss, low-noise signal transmission for monolithic integration of RF circuits and devices [1]-[5]. They often form microshield transmission lines [6]-[9] as shown in Fig. 1(a)-(c),

Manuscript received January 1, 2006; revised June 19, 2006. This work was supported by the National Science Foundation (NSF) under Grants ECS 0330963 and ECS-0115222 and was partially presented as "Skin Effects Aggregated Heating in RF MEMS Suspended Structures," at the IEEE MTT-S International Microwave Symposium (IMS2005), Long Beach, CA, June 12-17, 2005. Subject Editor C. Hierold.

L. L. W. Chow, K. Saitou, and K. Kurabayashi are with the Department of Mechanical Engineering, University of Michigan, Ann Arbor, MI 48109-2125 USA (e-mail: lindchow@umich.edu; kazu@umich.edu; katsuo@umich.edu).

Z. Wang is with Ansoft Corporation, San Jose, CA 95129 USA (e-mail: zwang@ansoft.com).

B. D. Jensen is with the Department of Mechanical Engineering, Brigham Young University, Provo, UT 84602 USA (e-mail: bdjensen@ byu.edu).

J. L. Volakis is with the Department of Electrical and Computer Engineering, Ohio State University, Columbus, OH 43212 USA (e-mail: volakis@ece.osu. edu).

Color versions of Figs. 3, 6, 9, and 11 are available online at http://ieeexplore. ieee.org.

Digital Object Identifier 10.1109/JMEMS.2006.883581

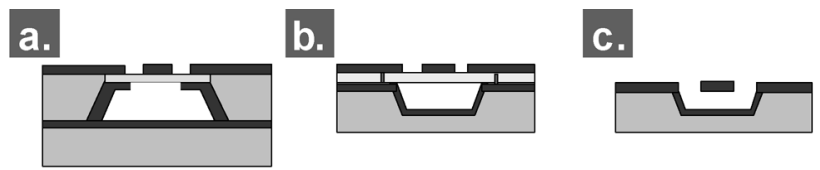

Lossy Substrate (e.g. Doped Silicon Wafer for CMOS Fabrication, $\sim 10 \Omega-\mathrm{cm}$ )

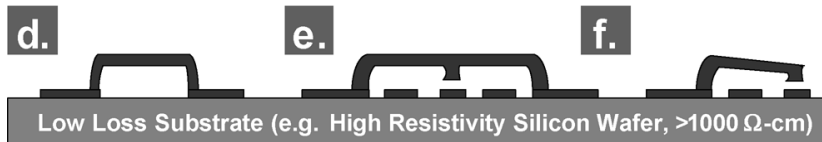

Fig. 1. Commonly used configurations of suspended MEMS transmission-line structures: (a) microshield structure with two bonded wafers and backside through-wafer etching [7]; (b) single-wafer frontside-etched microshield structure with vias on a thin membrane [8]; (c) single-wafer frontside-etched microshield structure without membrane; (d) suspended structure with/without dielectric support posts [21]; (e) fixed-fixed beam switch; and (f) down-state cantilever beam switch

and there is a wide variety of other RF microelectromechanical systems (MEMS) devices incorporating their structures, including LC passives [10], [11], filters [12], [13], power dividers [14], [15], mixers [16], [17], varactors [18], [19], couplers [20], [21], phase shifters [22], [23], resonators [24], [25], diplexers [24], oscillators [1], [24], parametric amplifiers [26], impedance tuners [27], [28], frequency selective surfaces [29], [30], and antennas [31], [32]. They can also take the form of moving beams to construct inline and shunt switches [22], [33], [34] as illustrated in Fig. 1(e) (fixed-fixed/double-clamped beam) and Fig. 1(f) (cantilever/clamped-free beam).

Despite the promise of MEMS technology to future wireless communications applications, self-heating is a major reliability concern for air-suspended RF MEMS transmission-line structures. The air gap limits thermal transport paths, thereby yielding large thermal resistance from the active region to the substrate. Furthermore, high-frequency signal transmission results in localized current appearing primarily near the conductor surface due to skin effects [35], and is responsible for significantly larger temperature increase as compared to direct current (dc) operation. Melting, creep, and thermal-strain-induced buckling result from the skin-effect heating, causing serious limitations on the power handling of air-suspended RF MEMS transmission-line structures.

Our previous study [36] suggests that buckling occurs at a lowest temperature and is therefore the most significant among the thermal failure modes. A permanent shape change can unavoidably alter the RF performance (e.g., characteristic impedance and capacitance) of MEMS devices incorporating transmission-line structures. As a result, thermal reliability issues must be overcome with proper designs of the air-suspended 
TABLE I

CANDidATES OF SOME Micron-Resolution TeMPERATURE MEASUREMENT TECHNIQUES

\begin{tabular}{|c|c|c|}
\hline Techniques & Advantage(s) & Disadvantage(s) \\
\hline $\begin{array}{l}\text { Thermocouple/ } \\
\text { RTD }\end{array}$ & $\begin{array}{l}\text {-fast } \\
\text {-precise } \\
\text {-reasonable cost }\end{array}$ & $\begin{array}{l}\text { - direct contact needed } \\
\text { - errors due to unknown contact resistance }\end{array}$ \\
\hline $\begin{array}{l}\text { Infra-red } \\
\text { Microscope }\end{array}$ & $\begin{array}{l}\text {-fast } \\
\text {-non-contact }\end{array}$ & $\begin{array}{l}\text { - tedious calibration } \\
\text { - emissivity characterization required } \\
\text { - high cost for high resolution ( } \sim 5 u m)\end{array}$ \\
\hline $\begin{array}{l}\text { Laser Thermo- } \\
\text { reflectance } \\
\text { Method }\end{array}$ & $\begin{array}{l}\text {-qualitatively } \\
\text { accurate }\end{array}$ & $\begin{array}{l}\text { - additional calibration needed } \\
\text { - sensitive optical alignment required } \\
\text { - expensive. } \\
\text { - bulky. }\end{array}$ \\
\hline $\begin{array}{l}\text { Scanning } \\
\text { Thermal } \\
\text { Microscopy }\end{array}$ & $\begin{array}{l}\text {-most precise } \\
\text {-accurate }\end{array}$ & $\begin{array}{l}\text { - direct contact required } \\
\text { - errors due to unknown contact resistance } \\
\text { - slow scanning speed } \\
\text { - expensive equipment cost }\end{array}$ \\
\hline $\begin{array}{l}\text { Electro-opto- } \\
\text { thermal probe }\end{array}$ & $\begin{array}{l}\text {-precise } \\
\text {-accurate } \\
\text {-non-contact }\end{array}$ & $\begin{array}{l}\text { - difficult calibration due to electro-opto- } \\
\text { thermal coupling effects }\end{array}$ \\
\hline $\begin{array}{l}\text { 4-wire } \\
\text { Measurement }\end{array}$ & $\begin{array}{l}\text {-fast } \\
\text {-accurate } \\
\text {-can be easily } \\
\text { implemented } \\
\text { on RF MEMS } \\
\text { structures for } \\
\text { in-situ } \\
\text { measurement }\end{array}$ & $\begin{array}{l}\text { - careful sample design and fabrication } \\
\text { needed }\end{array}$ \\
\hline
\end{tabular}

transmission-line structures. Previous work in power handling studies of RF MEMS switches include RF self-biasing [37], electromigration of electroplated gold [38], localized heating simulations [36], [39], and measurement using electro-optothermal probes [25]. However, limited research has been performed to systematically investigate the impact of skin effects on self-heating and thermal reliability of suspended RF MEMS transmission-line structures. It should be noted that sputtered gold structures have at least three times better resistance to electromigration with maximum sustainable current density of $20-35 \mathrm{GA} / \mathrm{m}^{2}$ in $150^{\circ} \mathrm{C}$ [41] than electroplated ones with maximum sustainable current density of $6 \mathrm{GA} / \mathrm{m}^{2}$ [38]. This requires us to carefully consider other failure mechanisms than electromigration for RF MEMS transmission-line structures made of sputtered gold.

Table I summarizes candidate techniques for MEMS-scale thermal characterization. Among them, we identify dc electrical resistance thermometry (based on the four-wire measurement technique [42]) as the most suitable approach for fast and accurate temperature sensing required in our paper. In general, the four-wire measurement technique can be implemented without sophisticated equipment and difficult calibration procedures [43]. This technique has limited spatial resolution as compared to other scanning thermal probe methods.

As shown later, the device of our interest is found to fail by buckling before local creep or melting occurs. Buckling is more affected by the overall device temperature increase than by the peak local temperature. Therefore, we believe that dc electrical resistance thermometry is most promising for our study as it provides quantitative information on the spatially averaged device temperature. To our knowledge, no previous work demonstrated use of this technique for thermal characterization of RF MEMS devices. In this paper, we propose a new experimental methodology to adopt dc electrical resistance thermometry for RF applications.

Specifically, this paper studies the thermal behavior of airsuspended RF MEMS coplanar waveguide (CPW) transmission lines experiencing self-heating due to skin effects, which limits their power handling capability. We apply both modeling and experimental methods to demonstrate the frequency-dependent temperature increase at various RF power levels. The approach that we adopt here is based on our recent preliminary research developments [44]. This paper extends them to obtain more insight into design rules.

First, we use our previous model integrating full-wave electromagnetics with heat conduction theory to design the dimensions of MEMS transmission lines [45]-[47]. We then proceed to show that a drastically simplified electrothermal model leading to a closed-form analytical solution can yield similar simulation results as compared to the vigorous model. Subsequently, we develop an in situ experimental technique to measure the temperature of RF MEMS transmission lines to validate our models. Last, using the experimentally validated analytical model, we predict the upper bound for power handling of RF MEMS transmission lines of varying dimensions and materials. The model and experimental technique developed in this paper can guide the design of RF MEMS components with improved thermal reliability and power handling.

\section{MODELING APPROACHES}

\section{A. EM EFE-BI-Coupled Thermal FEM Simulation}

To accurately account for all electrical losses in the suspended structure, we first carried out a full-wave electromagnetic (EM) simulation using the extended finite element-boundary integral (EFE-BI) method with a preconditioner [47]. The heat conduction equation can then be solved via a two-dimensional (2-D) thermal finite element model to evaluate the heat source density [36], [45], [46]. This integrated modeling is very accurate in capturing all the electromagnetic effects including losses due to substrate, surface radiation, and current crowding at the width edges, namely, the edge effect. However, the resulting solution matrix is highly ill-conditioned for such small MEMS dimensions $(<0.001$ wavelength), requiring half an hour processing time on a Pentium PC with a good preconditioner. This motivates us to explore an analytical model to minimize computational requirements for device design.

\section{B. Analytical Thermal Model for Skin Effects}

Our simulations show that on a typical $(<100 \mu \mathrm{m}$ wide $)$ MEMS transmission-line structure, the edge effects and electromagnetic radiation loss at its top surface are minimal as compared to the skin effect even at frequencies above $100 \mathrm{GHz}$. It is also shown that the spatial variation of the current concentrated within the skin depth is negligibly small. As such, we proceed to develop a thermal model that only captures the skin effect, as in Fig. 3, and approximate the RF equivalent current distribution to be uniform. Accordingly, the RF power delivered to the load is given by $P_{\mathrm{RF}}=I_{\mathrm{RF}}^{2} Z_{0}$, where $Z_{0}=50 \Omega$ is the characteristic line impedance, and $I_{\mathrm{RF}}$ denotes the RF current. 


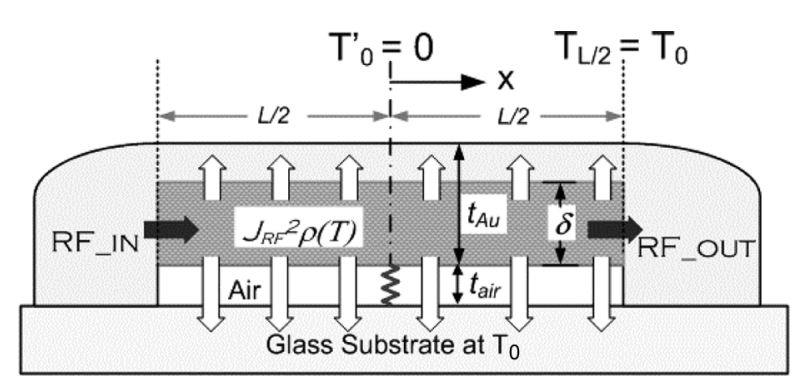

Fig. 2. Schematic diagram for our proposed analytical thermal model.

Further, we assume only one skin depth of penetration and take the RF current density $J_{\mathrm{RF}}$ to be uniform as well. We remark that the thickness of the suspended beam is designed to always be at least one skin-depth thick. Specifically, a $2.7-\mu \mathrm{m}$-thick beam is 1.1 times the skin depth of $2.4 \mu \mathrm{m}$ at $2 \mathrm{GHz}, 2.9$ times (skin depth is $0.93 \mu \mathrm{m}$ ) at $13.5 \mathrm{GHz}$, and 3.4 times (skin depth is $0.8 \mu \mathrm{m}$ ) at $18 \mathrm{GHz}$. Taking the ratio of the power used in our model to the total power dissipated in a semi-infinite conductor, we can then estimate the model errors to be $11 \%, 0.30 \%$, and $0.11 \%$ at $2,13.5$, and $18 \mathrm{GHz}$, respectively. That is, the largest error is at $2 \mathrm{GHz}$, and as the frequency increases the error becomes negligible. Further, since most of the transmission-line structures have uniform width $w$ and the major objective of the paper is to provide simple analytical formulae (as compared to numerical simulations) we can resort to these one-dimensional (1-D) models. As expected, the simplified analytical formulae will serve to aid thermal design rules and to allow for material property sensitivity studies with fewer computational requirements while capturing the essential physics. Our simulations show that on a typical $(<100 \mu \mathrm{m}$ wide) MEMS transmission-line structure, the edge effects and electromagnetic radiation loss at its top surface are minimal as compared to the skin effect even at frequency above $100 \mathrm{GHz}$. It is also shown that the spatial variation of current concentrated within the skin depth is negligibly small. As such, we proceed to develop a thermal model that only captures the skin effect, as in Fig. 2, and approximate RF equivalent current distribution to be uniform. According to the zeroth-order RF-simulation approach, the RF power delivered to the load is given by $P_{\mathrm{RF}}=I_{\mathrm{RF}}^{2} Z_{0}$, where $Z_{0}=50 \Omega$ is the characteristic line impedance and $I_{\mathrm{RF}}$ is the RF equivalent current.

In most MEMS structures, conduction is the dominant heat transfer mode as compared to convection and radiation, which constitute less than $1 \%$ of the total heat transfer due to their small surface areas. In this case, the main conductive paths for heat dissipation are across the gold suspended structure (with thermal conductivity $k_{\mathrm{Au}}$ and thickness $t_{\mathrm{Au}}$ ) and through the air gap $\left(k_{\text {air }}, t_{\text {air }}\right)$ under the suspended structure.

With the aforementioned assumptions, we begin the thermal characterization by considering a steady-state heat conduction governing equation

$$
t_{\mathrm{Au}} \frac{d}{d x}\left(k_{\mathrm{Au}} \frac{d T}{d x}\right)+J_{\mathrm{RF}}^{2} \delta \rho=\frac{k_{\mathrm{air}}}{t_{\mathrm{air}}}\left(T-T_{0}\right)
$$

subject to the boundary conditions

$$
\left.\frac{d T}{d x}\right|_{x=0}=\left.0 \quad T\right|_{x=\frac{L}{2}}=T_{0}
$$

A zero-heat-flux boundary condition is applied at the middle of the suspended structure because of its geometrical symmetry, and the temperatures at the both ends of the structure are assigned to be ambient temperature. The latter boundary condition is based on our measurement using a thermocouple that shows a negligible increase in the temperature at the device anchor regions during the thermal characterization described in Section III. We believe that it is because the gold metallization and the RF probes could both well serve for heat spreading and heat sinking in our device thermal characterization. The suspended structure length $L$ and the thermal conductivities of the materials $k_{\mathrm{Au}}$ and $k_{\text {air }}$ are assumed constant with temperature. Further, the effective current density $J_{\mathrm{RF}}$ and the resistivity $\rho$ are given by

$$
\begin{aligned}
J_{\mathrm{RF}} & =\frac{1}{w \delta} \sqrt{\frac{P_{\mathrm{RF}}}{Z_{0}}} \\
\rho & =\rho_{0}\left[1+\alpha_{t}\left(T-T_{0}\right)\right]
\end{aligned}
$$

where we assume a linear variation with temperature. In (4), $\alpha_{t}$ is the temperature coefficient of resistivity (TCR) and $\rho_{0}$ is the electrical resistivity at the ambient temperature.

The skin depth $\delta$ varies with frequency $f$ as [35]

$$
\delta=\sqrt{\frac{\rho}{\pi \mu f}}
$$

where $\mu, 4 \pi \times 10^{-7} \mathrm{H} / \mathrm{m}$, is the permeability of gold. Substituting (3)-(5) into (1) yields

$$
\begin{aligned}
k_{\mathrm{Au}} t_{\mathrm{Au}} \frac{d^{2} T}{d x^{2}}+\left(\frac{P_{\mathrm{RF}}}{Z_{0} w^{2}}\right) \sqrt{\pi \mu \rho_{0} f\left[1+\alpha_{t}\left(T-T_{0}\right)\right]} \\
=\frac{k_{\text {air }}}{t_{\text {air }}}\left(T-T_{0}\right) .
\end{aligned}
$$

We note that $\alpha_{t}\left(T-T_{0}\right)<1$ and it is of interest to linearize (6), so we introduce the Taylor's expansion

$$
\sqrt{1+\alpha_{t}\left(T-T_{0}\right)} \approx 1+\frac{1}{2} \alpha_{t}\left(T-T_{0}\right)
$$

to get

$$
\begin{array}{r}
k_{\mathrm{Au}} t_{\mathrm{Au}} \frac{d^{2} T}{d x^{2}}+\left(\frac{P_{\mathrm{RF}}}{Z_{0} w^{2}}\right) \sqrt{\pi \mu \rho_{0} f}[1+ \\
\left.+\frac{1}{2} \alpha_{t}\left(T-T_{0}\right)\right] \\
=\frac{k_{\mathrm{air}}}{t_{\mathrm{air}}}\left(T-T_{0}\right) .
\end{array}
$$

Solving (8) subject to the boundary conditions in (2) leads to

$$
\Delta T=T-T_{0}=\frac{\beta}{\gamma^{2}}\left[1-\frac{\cosh (\gamma x)}{\cosh \left(\frac{\gamma L}{2}\right)}\right]
$$

where

$$
\gamma^{2}=\frac{k_{\mathrm{air}}}{k_{\mathrm{Au}} t_{\mathrm{Au}} t_{\mathrm{air}}}-\frac{\alpha_{t} \beta}{2}
$$




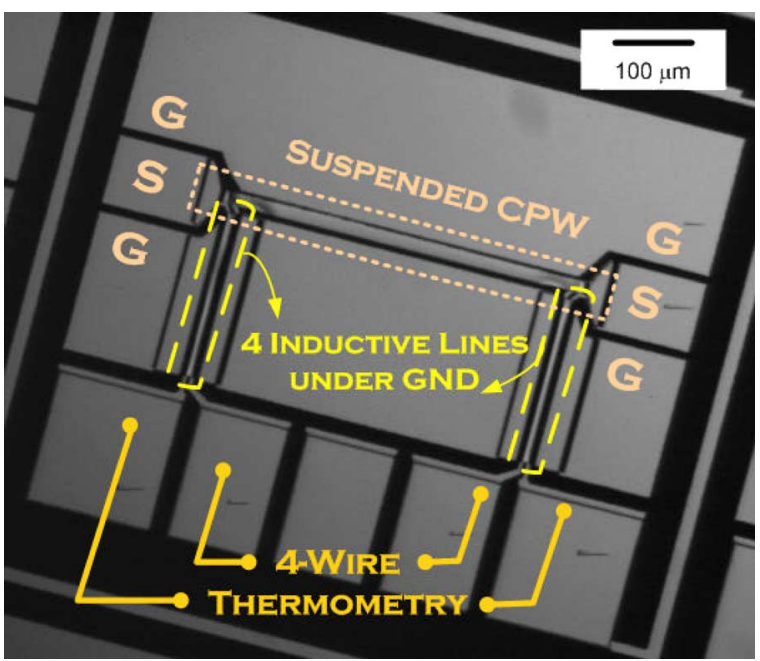

Fig. 3. Optical image of a suspended CPW for average temperature measurement.

and

$$
\beta=\frac{P_{\mathrm{RF}}}{k_{\mathrm{Au}} t_{\mathrm{Au}} w^{2} Z_{0}} \sqrt{\pi \mu \rho_{0} f} .
$$

From this result, we note that the peak/maximum temperature rise is at the middle of the beam, and is given by

$$
\left.\Delta T\right|_{x=0}=\frac{\beta}{\gamma^{2}}\left[1-\frac{1}{\cosh \left(\frac{\gamma L}{2}\right)}\right]
$$

with the corresponding average temperature rise across the suspended structure $T_{\text {avg }}$ given by

$$
\Delta T_{\mathrm{avg}}=\frac{\beta}{\gamma^{2}}\left[1-\frac{2}{\gamma L} \tanh \left(\frac{\gamma L}{2}\right)\right] .
$$

In Section III, we describe experiments designed to validate this closed-form thermal model and to generate design rules.

\section{EXPERIMENTS}

Among various types of transmission lines such as microstrip and slot lines, CPWs are popular in use because they do not add additional inductance at the RF ground. We can also readily measure the RF performance directly using RF ground-signal-ground $(\mathrm{G}-\mathrm{S}-\mathrm{G})$ probes without adapting additional connectors. Therefore, we will employ the CPW design for the MEMS structure, as shown in Fig. 3.

\section{A. Micron Resolution DC-RF Decoupled In Situ Temperature Measurement Technique Development}

Our four-wire measurement configuration is implemented by adding four on-chip inductive transmission lines at the two ends of the signal line of the suspended CPW. The basic temperature sensing mechanism is as follows: With RF power passing through it, the suspended CPW heats up, accompanied by a linear rise in electrical resistivity with temperature. The subject-suspended CPW is also fed with a small dc current and the corresponding dc voltage is measured. The average temperature
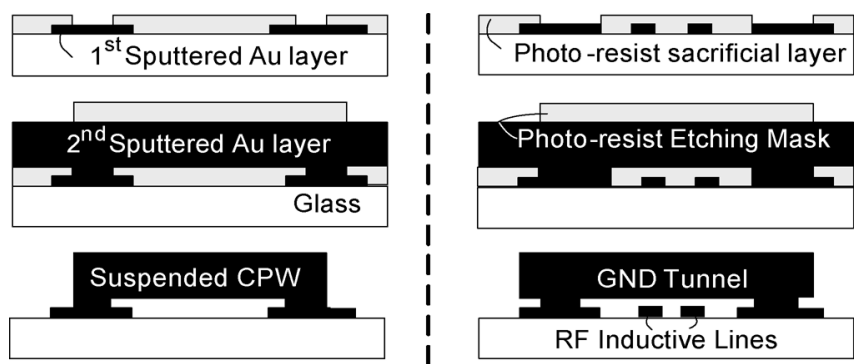

Fig. 4. Fabrication process of the suspended CPW and the ground (GND) tunnel for RF inductive lines.

rise of the entire suspended CPW is then obtained through precisely extracting the change in resistivity from the measured dc voltage and applied dc current. It is important to note that the dc current adds negligible power towards temperature rise $(<1 \%)$ during the RF operation.

With some design care, we can achieve high accuracy in the temperature extraction process. As both dc and RF power are present, the dc and RF circuits must be decoupled from each other. This is achieved using the on-chip RF inductive transmission lines and an off-chip dc blocking capacitor. The on-chip inductors were chosen because they are small and compact, and they eliminate losses due to off-chip wiring. Also, the off-chip blocking capacitors were chosen to avoid large parasitic capacitance with the substrate and CPW ground lines, and because an on-chip capacitor would be quite large.

\section{B. Device Design and Fabrication}

We designed the RF MEMS suspended CPW transmission lines with a four-wire thermometric circuitry to yield minimum return loss $S_{11}$ and insertion loss $S_{21}$. The designs of purely suspended CPWs were first based on a closed-form conformal mapping method and the commercial software: ADS Momentum 2003A (Agilent). The four-wire temperature sensing circuits that included inductive lines as RF chokes and probe pads were then added to the suspended CPW structure. Prior to doing so, we used IE3D 10.0 (Zeland) to ensure that it blocks RF signals.

Most microwave components are made of gold to achieve low resistivity and inertness to oxidation. The suspended CPW transmission lines tested here were fabricated using gold surface micromachining. It should be noted, however, that this temperature measurement technique can be applicable to any electrically conductive material such as aluminum and copper.

A $30-\mathrm{nm} \mathrm{Cr} / 1-\mu \mathrm{m}-\mathrm{Au}$ thin film was initially sputtered on a glass substrate and lithographically patterned the probe pads and four inductive lines, as shown in Fig. 4. A photoresist sacrificial layer of $3 \mu \mathrm{m}$ was then spun-on to define the anchor. Also, a 2.7- $\mu \mathrm{m}$-Au thin film was sputtered as the suspended CPW signal lines, and the ground tunnel above the four inductive lines. After the suspended structures were patterned and wet-etched, we proceeded with die-sawing, sacrificial layer removal, and finally $\mathrm{CO}_{2}$ critical dry. In total, this process requires only three masks.

\section{Setup and Calibration}

Fig. 5 shows the experimental setup for our RF power-temperature measurements. To maximize thermal sensitivity, the 


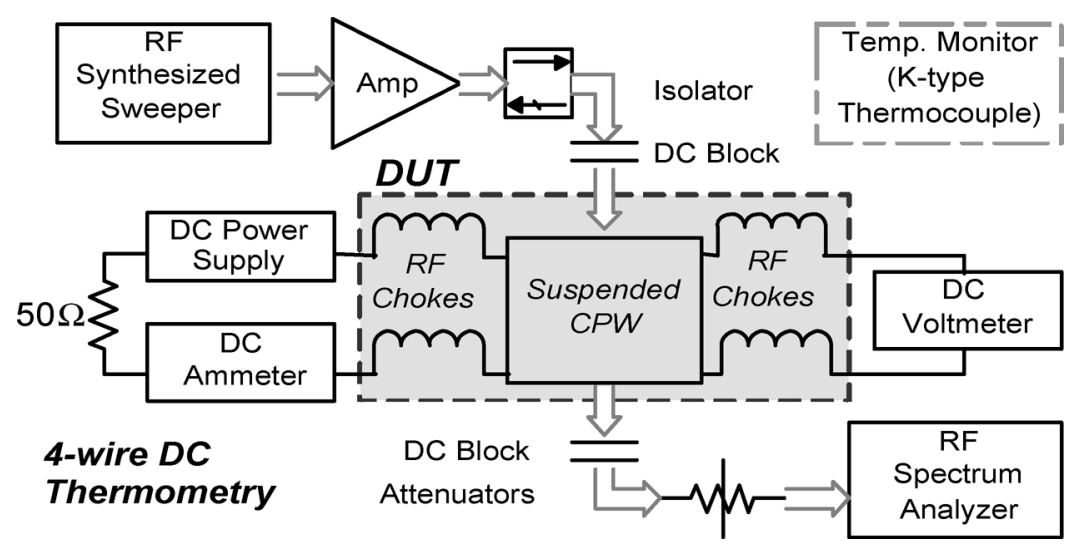

Fig. 5. Schematic setup diagram for the RF power-temperature measurement.

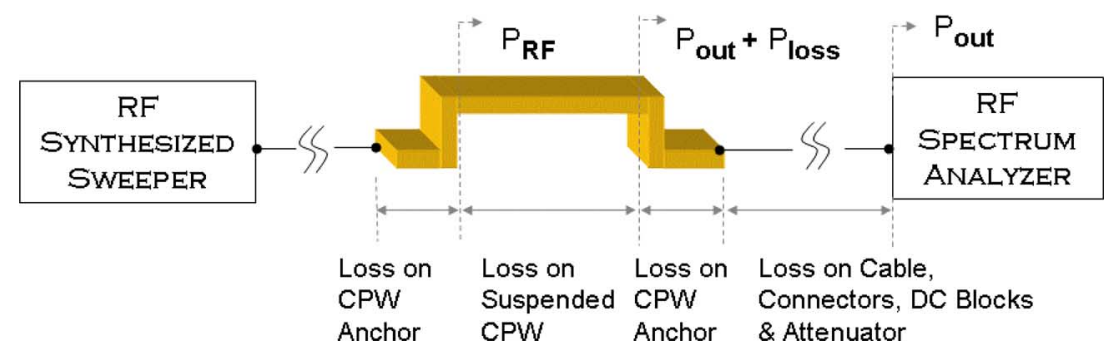

Fig. 6. Power losses during calibration of input power delivered to the suspended CPW $P_{\mathrm{RF}}$.

suspended CPW was tested over a range of RF power from low to very high, up to the equipment specifications. To do so, the RF power from an RF synthesized sweeper (HP 8364A) was fed into a power amplifier (Hughes Research: K-band, X-band traveling wave tubes, and Miteq: $1-2 \mathrm{GHz}$ amplifier for $18,13.5$, and $2 \mathrm{GHz}$, respectively) to the suspended CPW through an isolator and dc blocks, and was monitored using a spectrum analyzer (HP 8562A). The four-wire thermometric dc circuitry was connected to the suspended CPW via four on-chip RF inductive lines as shown in Fig. 3. A $50 \mathrm{~mA}$ dc was generated from a dc power supply (HP E3630A), estimated to have a contribution less than $1 \%$ to the total temperature rise. The dc voltage was then measured by the 6.5-digit multimeter (HP 34401A). The ambient temperature was monitored using a K-type thermocouple with a $0.5^{\circ} \mathrm{C}$ accuracy rating.

Prior to RF power-temperature testing, dielectric power loss due to the substrate and radiation loss to the air were both calibrated using network analyzer (HP8517B $S$-parameter test set) from 0.5 to $20 \mathrm{GHz}$. Here, we first characterized a standard (nonsuspended) CPW line patterned on the same substrate. These losses were found to be negligible for the whole range of the frequency $\left(<0.1 \mathrm{~dB}\right.$ for $\left.S_{21}\right)$. This allowed us to assume that the losses were even smaller for the suspended CPW. However, the current or impedance discontinuities at the two anchor structures supporting the suspended CPW are expected to cause additional insertion loss (while the air-suspension itself reduces the substrate loss). These losses need to be considered in our estimation of the RF power delivered to the CPW. The $S$-parameter measurements were all performed at very low RF power input $(<1 \mathrm{~mW})$ here, causing no self-heating to the devices under test.
Thus, these measurements involve negligible power loss due to resistive dissipation.

Fig. 6 shows the model used for the power losses in our RF power-temperature measurement setup. The RF power input at the suspended CPW $P_{\mathrm{RF}}=I_{\mathrm{RF}}^{2} Z_{0}$ was experimentally estimated by $P_{\mathrm{RF}}=P_{\text {loss }}+P_{\text {out }}$, where $P_{\text {loss }}$ is the total loss including cables, connectors, one CPW anchor, one dc block, and attenuator between the output end of the CPW and the spectrum analyzer, and $P_{\text {out }}$ is the RF power reaching the spectrum analyzer. $P_{\text {loss }}$ was carefully calibrated by connecting each of the circuit components between the RF power source and the spectrum analyzer, and $P_{\text {out }}$ was directly measured using the spectrum analyzer. The errors in determining $P_{\mathrm{RF}}$ here are estimated to be less than $4 \%$ accounting for the uncertainties in the losses for the suspended CPW. Three frequencies-2, 13.5, and $18 \mathrm{GHz}$-were chosen as they were found to yield a good impedance match from the $S$-parameter measurements.

\section{Temperature and RF Power Extraction}

Heating of the suspended beam causes its resistance to rise, resulting in a dc voltage difference $V_{\mathrm{dc}}$ across the beam, given by

$$
V_{\mathrm{dc}}=I_{\mathrm{dc}} R=I_{\mathrm{dc}} \frac{L}{w t} \rho_{0}\left(1+\alpha_{t} \Delta T_{\mathrm{avg}}\right) .
$$

To use (14), it is necessary to measure all dimensions accurately. Thus, dimensions such as thickness $t$, width $w$, and length $L$ were precisely measured with a surface profilometer (Dektak $6 \mathrm{M}$ ) and an interferometer (Zygo Newview 5000). The values 


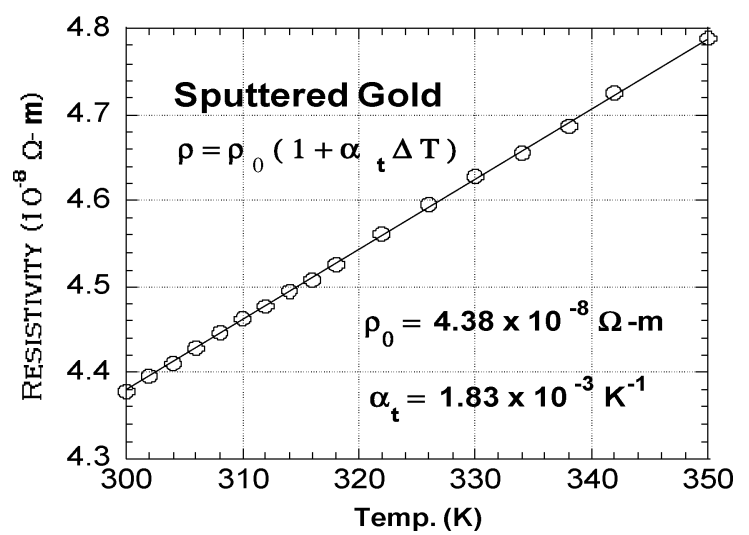

Fig. 7. Calibration curve of resistivity $\left(\rho_{0}\right), 4.38 \times 10^{-8} \Omega-\mathrm{m}$ and temperature coefficient of resistivity $\left(\alpha_{t}\right), 1.83 \times 10^{-3} \mathrm{~K}^{-1}$.

of $\alpha_{t}$ and $\rho_{0}$ were found to be $1.83 \times 10^{-3} \mathrm{~K}^{-1}$ and $4.4 \times$ $10^{-8} \Omega-\mathrm{m}$, respectively, using a van der Pauw structure heated by a temperature controlled thermal chuck. The data from this test are shown in Fig. 7. Considering all uncertainties, the measured temperature is within $2 \%$ of the experimental error measured in Celsius degree. The temperature sensitivity of $30 \mathrm{mV} / \mathrm{K}$ with a dc current input of $0.01 \mathrm{~A}$ can be estimated from

$$
\frac{\partial V_{\mathrm{dc}}}{\partial \Delta T_{\mathrm{avg}}}=\frac{\alpha_{t} I_{\mathrm{dc}} \rho_{0}}{d}\left(\frac{l}{w}\right)
$$

This sensitivity corresponds to temperature resolution of $0.3 \mathrm{~K}$, which is high among the temperature measurement techniques listed in Table I.

\section{RESULTS AND DISCUSSIONS}

\section{A. Model Prediction}

Our calculation based on the analytical expressions (12) and (13) predicts that a $0.5-\mathrm{W} R \mathrm{RF}$ power input results in a peak temperature rise of $112^{\circ} \mathrm{C}$ (average temperature rise of $73^{\circ} \mathrm{C}$ ) at $18 \mathrm{GHz}, 96^{\circ} \mathrm{C}\left(64^{\circ} \mathrm{C}\right)$ at $13.5 \mathrm{GHz}$, and $35^{\circ} \mathrm{C}\left(22^{\circ} \mathrm{C}\right)$ at $2 \mathrm{GHz}$. These are very close to the full-wave EM simulation results that predict a peak temperature rise (average temperature rise) of $115^{\circ} \mathrm{C}\left(77^{\circ} \mathrm{C}\right)$ at $18 \mathrm{GHz}, 99^{\circ} \mathrm{C}\left(67^{\circ} \mathrm{C}\right)$ at $13.5 \mathrm{GHz}$, and $37^{\circ} \mathrm{C}\left(24^{\circ} \mathrm{C}\right)$ at $2 \mathrm{GHz}$. Owing to the RF current edge effects, the full-wave model predicts a slightly higher temperature rise than the analytical model, but fairly good overall. This implies that the assumption used for our analytical model, which considers only the skin effect (neglecting the electron crowding near the edge of the CPW width, losses due to surface radiation, and substrate) is reasonable for modeling the heat transfer in MEMS structures at the radio frequencies.

As frequency increases, the skin depth becomes smaller and $J_{\mathrm{RF}}$ higher, giving out more heat in a localized region. This phenomenon deteriorates the reliability of RF MEMS suspended structures. As specifically shown in Fig. 8, a 3-W RF power input of $18 \mathrm{GHz}$ can result in a device temperature of $1376^{\circ} \mathrm{C}$ causing melting of the gold structure. This modeling work assumed an air gap on the order of microns, typical of the surface-micromachined suspended structures as in Fig. 1(d)-(f). It should be noted that the skin-effect heating will become more serious for microshield structures in Fig. 1(a)-(c) as their air

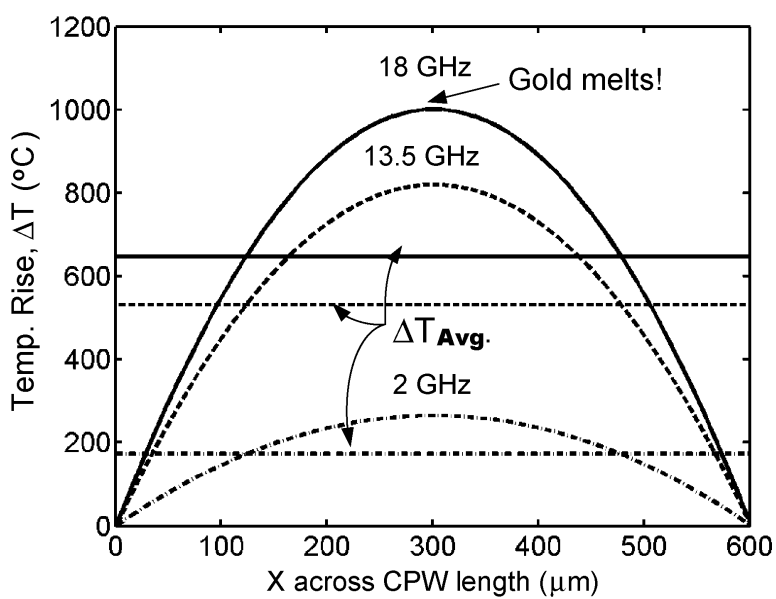

Fig. 8. "Parabolic" shape temperature-rise distribution $\Delta T$ along the suspended CPW. It is modeled via the EFE-BI for RF analysis and FEM for thermal modeling at $3-\mathrm{W}$ RF power. The horizontal lines indicate the corresponding average temperature rises $\Delta T_{\text {avg }}$.

gaps are typically a few hundred microns because the heat conduction via such air gaps becomes negligible.

\section{B. Isolation and Insertion Loss of Suspended CPW}

Fig. 9 indicates that the measured isolation loss $\left(S_{11}\right)$ data at low levels $(<-20 \mathrm{~dB})$ for our suspended CPW match well with the simulations based on IE3D (Zeland). The experimentally measured insertion losses $\left(S_{21}\right)$ of $-0.5 \mathrm{~dB}$ at $2 \mathrm{GHz},-0.8$ $\mathrm{dB}$ at $13.5 \mathrm{GHz}$, and $-1.0 \mathrm{~dB}$ at $18 \mathrm{GHz}$ imply $89 \%, 83 \%$, and 79\% RF power transmitted through the suspended CPW, which are common among RF MEMS suspended structure measurements [48]-[52]. Thus, we suspect that the discrepancy between the simulations and the experiments for $S_{21}$ in Fig. 9 could be the result of difficulties associated with modeling current or impedance discontinuities at the two anchor structures. As discussed in Section III-C, the discontinuities are expected to bring in the additional insertion losses in the experimental data. Although these losses were carefully considered in the RF power calibration for the suspended CPW, it is possible that the simulations could not fully include them. The self-heating of the suspended CPW line during the RF power-temperature measurements from ambient temperature to $150^{\circ} \mathrm{C}$ caused its total resistance to increase by 0.5 to $0.6 \Omega$. This translates into the fact that less than $4 \%$ of the carried RF power was dissipated as heat, hence, ensuring insignificant change in the $S$-parameter characteristics of the CPW line measurement system.

\section{Average Temperature Measurement With Various $R F$ Frequencies and RF Power Levels}

Fig. 10 plots the average temperature rise in the $616 \mu \mathrm{m}$ $\times 15 \mu \mathrm{m} \times 2.7 \mu \mathrm{m}$ suspended CPW at varying input RF power for three frequencies. The ambient temperature was monitored throughout the entire measurements to obtain accurate device temperature data. We observe that a $0.5-\mathrm{W}$ RF power can have an average temperature rise of $\sim 75^{\circ} \mathrm{C}$ at $18 \mathrm{GHz}, \sim 65^{\circ} \mathrm{C}$ at $13.5 \mathrm{GHz}$, and $\sim 20^{\circ} \mathrm{C}$ at $2 \mathrm{GHz}$. The 2 - and $18-\mathrm{GHz}$ curves are in good agreement with the predictions from (13) whereas the theoretical curve at $13.5 \mathrm{GHz}$ overpredicts the temperature rise 
TABLE II

List of Material Properties Used in Power Handling Prediction

\begin{tabular}{|l|c|c|c|}
\hline Material Properties & Gold & Aluminum & Copper \\
\hline Thermal Conductivity, $\mathrm{k}(\mathrm{W} / \mathrm{m}-\mathrm{K})$ & 317 & 237 & 401 \\
\hline Temperature Coefficient of Resistivity, $\alpha_{\mathrm{t}}\left(\mathrm{\times} 10^{-3} / \mathrm{K}\right)$ & 1.83 & 3.9 & 3.9 \\
\hline Electrical Resistivity at Ambient Temp, $\rho_{0},\left(\mathrm{x} 10^{-8} \Omega-\mathrm{m}\right)$ & 4.4 & 2.6 & 1.7 \\
\hline Coefficient of Thermal Expansion, $\alpha_{\mathrm{CTE}}(\mathrm{ppm})$ & 13.8 & 23 & 16 \\
\hline Young's Modulus, E (GPa) & 50 & 70 & 120 \\
\hline
\end{tabular}

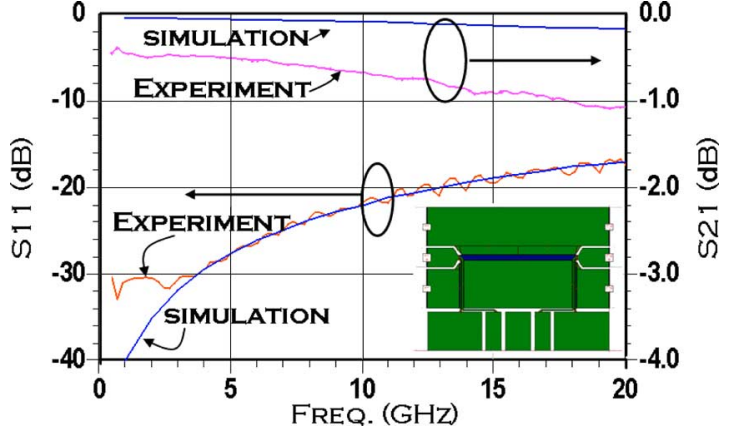

Fig. 9. Measured isolation $\left(S_{11}\right)$ and insertion $\left(S_{21}\right)$ losses of our suspended CPW structure.

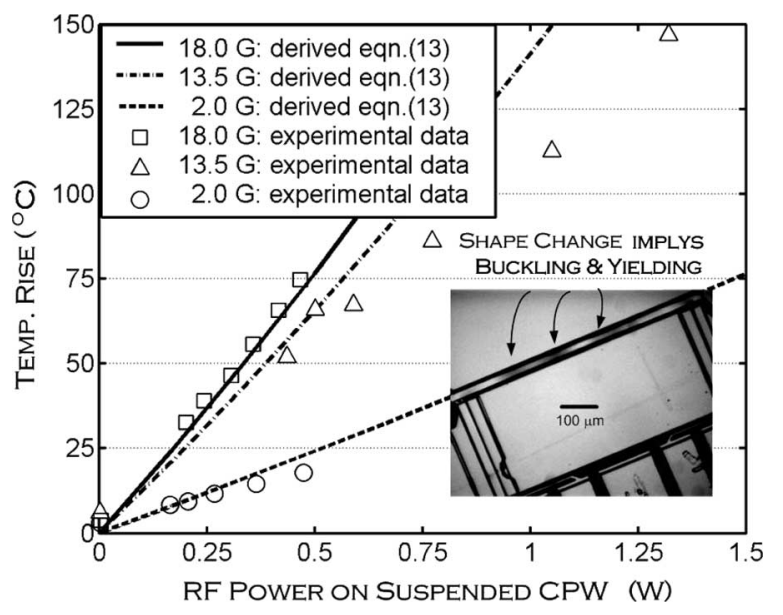

Fig. 10. Self-heating in the air-suspended CPW that increases with RF frequency due to skin-effects. The inset figure shows buckling and permanent plastic deformation observed during and after RF power measurement.

especially at the higher power levels as compared to measurements. This discrepancy is explained by the increased experimental uncertainties resulting from the high-power instability of the X-band traveling wave tube employed in our setup. Of importance is that the proposed analytical model primarily accounting for the skin effects yields reasonable agreement with the experimental results. This validated model is used in the following section to predict the upper bound for the power handling of a suspended transmission-line structure.

\section{POWER HANDLING PREDICTION}

Buckling and plastic yielding have been observed during testing as shown in the inset of Fig. 10. In fact, our experimentally validated analytical thermal model predicts that a stress-free $616 \mu \mathrm{m} \times 15 \mu \mathrm{m} \times 2.7 \mu \mathrm{m}$ suspended beam starts to buckle when the RF power is only $57 \mathrm{~mW}$ at $18 \mathrm{GHz}$. In this paper, we consider bucking as the most dominant thermomechanical failure mechanism that limits RF power handling. This assumption is based on our experimental observations and previous theoretical studies [23]. Buckling occurs when the thermal strain $\varepsilon_{t}$ exceeds the critical buckling strain

$$
\varepsilon_{t}=\alpha_{\mathrm{CTE}} \Delta T_{\mathrm{avg}} \geq\left[\frac{1}{3}\left(\pi \frac{t_{\mathrm{Au}}}{L}\right)^{2}+\frac{\sigma_{\text {residual }}}{E}\right] .
$$

Compressive residual stress $\left(\sigma_{\text {residual }}<0\right.$, typical for gold and copper) promotes buckling, whereas tensile residual stress ( $\sigma_{\text {residual }}>0$, typical for aluminum) suppresses the onset of failure. As can be seen in Fig. 11, RF power handling can be enhanced by geometry, residual stress, and material design. Shortening the length, increasing the width, thickening the structure, and having high tensile residual stress can avoid premature buckling. Apart from gold, copper and aluminum are also widely used in $\mathrm{RF} /$ microwave devices. The material properties used in these calculations for each material are shown in Table II. We observe that copper shows similar behavior to gold whereas aluminum requires more than double the tensile stress to reach the same level of power handling.

Since the width and length of transmission line structures, for instance, in filter designs, are determined by the device specification, and a specific residual stress of a thin film material might not be available in certain foundry, increasing thickness becomes the highly recommended solution. In practice, as an example, even a $200 \mu \mathrm{m} \times 100 \mu \mathrm{m} \times 1 \mu \mathrm{m}$ suspended beam can only handle $5-\mathrm{W}$ RF power at $20 \mathrm{GHz}, 3.3 \mathrm{~W}$ at $50 \mathrm{GHz}$, and $2.3 \mathrm{~W}$ at $100 \mathrm{GHz}$ in a stress-free state. If the failure is mainly caused by the skin effect and accompanying buckling, thickening the structures from 1 to $3 \mu \mathrm{m}$ increases the power handling to $125 \mathrm{~W}$ at $20 \mathrm{GHz}, 80 \mathrm{~W}$ at $50 \mathrm{GHz}$, and $56 \mathrm{~W}$ at $100 \mathrm{GHz}$, leading to a 25 -fold increase in power handling.

\section{SUMMARY AND CONCLUSION}

Skin-effect heating is a phenomenon unique to high-frequency operation and must be considered in designing RF MEMS devices. In this paper, we have studied the skin-effect heating of an air-suspended transmission-line structure, which is the building block component in microwave circuits. The major contributions of this paper include the following: 1) development of a closed-form electrothermal transport model capturing the important physics of skin effects; 2) development of a new in situ temperature measurement technique for RF MEMS devices; and 3) generation of design guidelines for air-suspended RF 

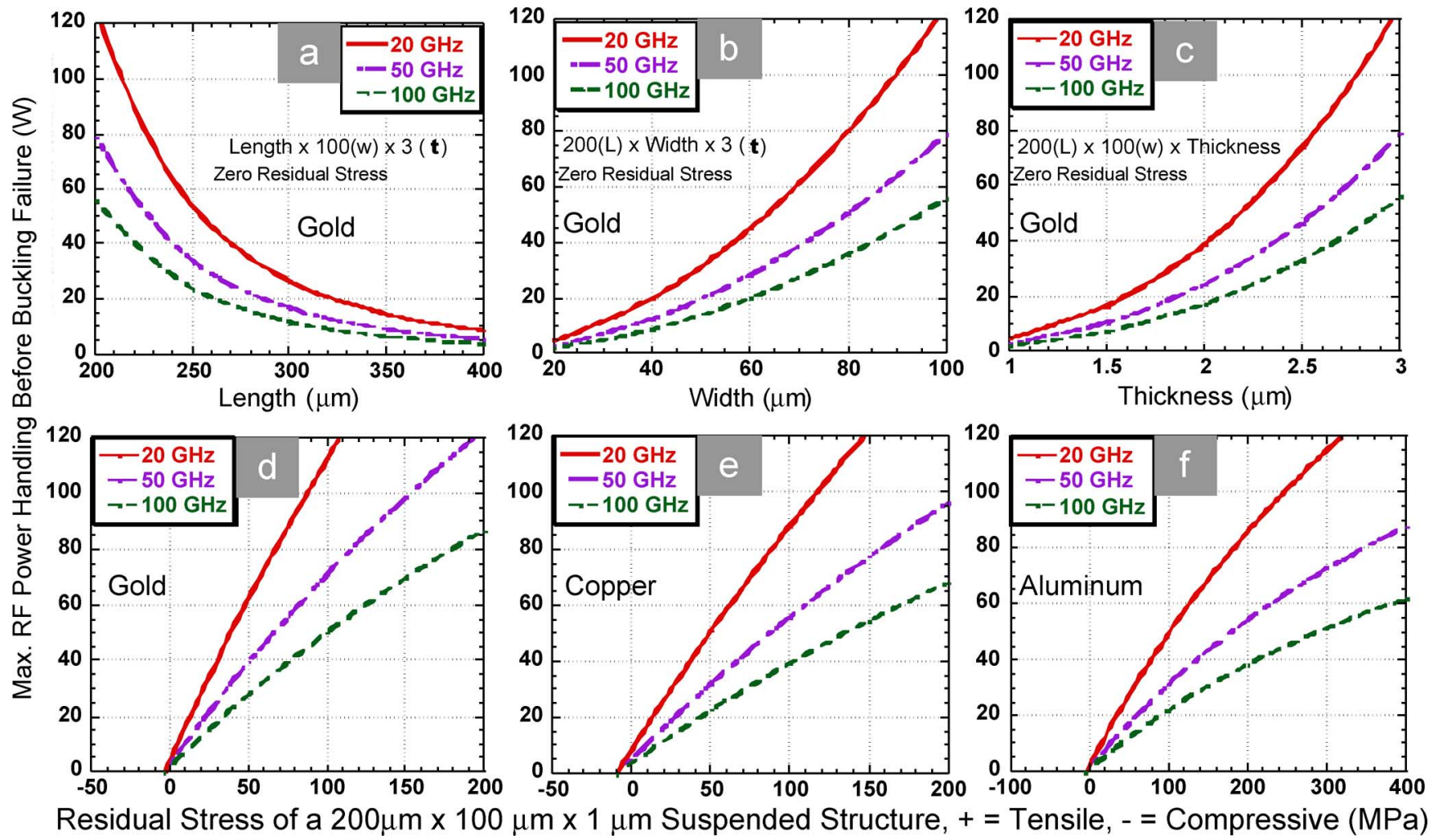

Fig. 11. Power handling prediction using the proposed closed-form analytical model with various geometry, material, and residual stress: (a) length, (b) width, (c) thickness, (d) gold, (e) copper, and (f) aluminum.

MEMS transmission-line structures to improve power handling and reliability.

The RF MEMS CPW structure dimensions in our experiments we designed using our previous full-wave electromagnetic numerical model using the EFE-BI method, coupled with a finite element thermal simulation. The results from these vigorous simulations and those from the closed-form analytical model show that the skin effects have the largest impact on self-heating. That is, the two models predict nearly the same values for the maximum and average temperature rises within $\pm 2 \%$ difference. Undeniably, the analytical model has the advantage of significantly less computational requirements.

The developed new experimental technique to accurately measure the spatially averaged temperature of the testing CPW structure incorporated a RF-dc decoupled thermometric circuit. This allows for in situ electrical resistance thermometry of the RF MEMS components based on the four-wire measurement technique. The obtained experimental results showed that the temperature increase is a strong function of frequency and gives rise to thermal-stress-induced structural instability and permanent shape change. Further, the obtained data show reasonably good agreement with our model predictions.

Using the experimentally validated model, we have investigated the influence of RF MEMS design parameters, including width, length, thickness, material properties, and residual stress on the RF power handling subject to buckling failure criteria. Most often, device specifications and process conditions impose limited flexibility in the width and length of transmission line structures, and in the control of residual stress. Therefore, increasing the transmission-line thickness is the most practical design approach to maximizing the power handling. In one example, an increase of the thickness by $2 \mu \mathrm{m}$ can substantially decrease temperature rise and thus permits the air-suspended RF MEMS CPW to transmit greater than 25-fold more RF power.

\section{ACKNOWLEDGMENT}

The authors would like to thank Dr. B. J. J. Hung and Prof. G. M. Rebeiz from the University of Michigan Terahertz Integrated Circuit Lab for helpful assistance and fruitful discussions on RF power experiments.

\section{REFERENCES}

[1] E.-C. Park and E. Yoon, "A $13 \mathrm{GHz}$ CMOS distributed oscillator using MEMS coupled transmission lines for low phase noise," in Proc. IEEE Int. Solid-State Circuit Conf., 2004, vol. 1, pp. 300-301, pt. 1.

[2] L. E. Larson, R. H. Hackett, M. A. Melendes, and R. F. Lohr, "Micromachined microwave actuator (MIMAC) technology-a new tuning approach for microwave integrated circuits," in Proc. IEEE Microw. Millimeter-Wave Monolithic Circuits Symp. Dig., 1991, pp. 27-30.

[3] L. P. B. Katehi, G. M. Rebeiz, T. M. Weller, R. F. Drayton, H.-J. Cheng, and J. F. Whitaker, "Micromachined circuits for millimeter- and submillimeter-wave applications," IEEE Antennas Propagat. Mag., vol. 35, no. 5, pp. 9-17, Oct. 1993.

[4] C. T.-C. Nguyen, L. P. B. Katehi, and G. M. Rebeiz, "Micromachined devices for wireless communications," Proc. IEEE, vol. 86, no. 8, pp 1756-1768, Aug. 1998

[5] H. A. C. Tilmans, W. De Raedt, and E. Beyne, "MEMS for wireless communications: From RF-MEMS components to RF-MEMS-SiP," $J$. Micromech. Microeng., vol. 13, no. 4, pp. S139-S163, Jul. 2003.

[6] A. G. Engel and L. P. B. Katehi, "Low-loss monolithic transmission lines for submillimeter and terahertz frequency applications," IEEE Trans. Microw. Theory Tech., vol. 39, no. 11, pp. 1847-1854, Nov. 1991. 
[7] N. I. Dib, W. P. Harokopus, Jr., P. B. Katehi, C. C. Ling, and G. M. Rebeiz, "Study of a novel planar transmission line," in Proc. IEEE MTT-S Int. Microw. Symp. Dig., 1991, vol. 2, pp. 623-626.

[8] Y. Yoshida, T. N. Nishino, J. Jiao, S.-S. Lee, Y. Suehiro, K. Miyaguchi, T. Fukami, M. Kimata, and O. Ishima, "A grounded coplanar waveguide with a metallized silicon cavity fabricated by front-surface-only processes," Sens. Actuators A: Phys., vol. 111, no. 1, pp. 129-134, 2004.

[9] S. Chen and Y. Liu, "Analysis and calculation of the micro-shield line," Tien Tzu Hsueh Pao/Acta Electronica Sinica, vol. 26, no. 6, pp. 71-73, 1998, 81.

[10] C.-Y. Chi and G. M. Rebeiz, "Planar millimeter microstrip lumped elements using micro-machining techniques," in Proc. IEEE MTT-S Int. Microw. Symp. Dig., 1994, vol. 2, pp. 657-660.

[11] S.-S. Lee, Y. Yoshida, T. Nishino, Y. Suehiro, and T. Fukami, "Simultaneous implementation of various RF passives using a novel RF MEMS process module and metallized air cavity," J. Micromech. Microeng., vol. 15, no. 3, pp. 441-446, Mar. 2005.

[12] S. V. Robertson, L. P. B. Katehi, and G. M. Rebeiz, "W-band microshield low-pass filter," in Proc. IEEE MTT-S Int. Microw. Symp. Dig., 1994, vol. 2, pp. 625-628.

[13] T. Zhou and A. M. Robinson, "Tunable CMOS MEMS electromechanical bandpass filters," Can. J. Electr. Comput. Eng., vol. 27, no. 1, pp. 17-21, Jan. 2002.

[14] T. M. Weller, L. P. B. Katehi, M. I. Herman, and P. D. Warnhof, "Membrane Technology (MIST-T) applied to microstrip: A $33 \mathrm{GHz}$ Wilkinson power divider," in Proc. IEEE MTT-S Int. Microw. Symp. Dig., 1994, vol. 2, pp. 911-914.

[15] M. Unlu, K. Topalli, H. Sagkol, S. Demir, O. A. Civi, S. S. Koc, and T. Akin, "RF MEMS adjustable impedance matching network and adjustable power divider," in Proc. IEEE Antennas Propagat. Int. Symp., 2002, vol. 2, pp. 26-29.

[16] T.-H. Lee, J. R. East, C.-Y. Chi, G. M. Rebeiz, R. J. Dengler, P. H. Siegel, and G. I. Haddad, "The fabrication and performance of planar doped barrier diodes as $200 \mathrm{GHz}$ subharmonically pumped mixers," IEEE Trans. Microw. Theory Tech., vol. 42, no. 4, pp. 742-749, Apr. 1994.

[17] T. Buck, M. Reimann, M. Ulm, R. Mueller-Fiedler, J. Seidel, E. Kasper, C. Schoellhorn, and S. Haak, "Monolithic integration of RF-MEMS and semiconductor devices for the K-band," Proc. SPIE-Int. Soc. Opt. Eng., vol. 4981, pp. 131-138, 2003.

[18] D. J. Young and B. E. Boser, "A micromachined variable capacitor for monolithic low-noise VCOs," in Proc. Solid-State Sens. Actuators Workshop, Jun. 1996, pp. 86-89.

[19] Z.-W. Liu, J. Wei, Y. Wang, J. Fang, L.-T. Liu, and Z.-J. Li, "Analysis and optimization of a side pull-down electrodes controlled MEMS varactor," Opt. Precision Eng., vol. 13, no. 2, pp. 135-143, Apr. 2005.

[20] S. V. Robertson, L. P. B. Katehi, and G. M. Rebeiz, "A 10-50 GHz micromachined directional coupler," in Proc. IEEE MTT-S Int. Microw. Symp. Dig., 1996, vol. 2, pp. 797-800.

[21] S.-C. Kim, B.-S. Ko, T.-J. Baek, B.-O. Lim, A. Dan, D.-H. Shin, and J.-K. Rhee, "Hybrid ring coupler for W-band MMIC applications using MEMS technology," IEEE Microw. Wireless Compon. Lett., vol. 15, no. 10, pp. 652-654, Oct. 2005.

[22] N. S. Barker and G. M. Rebeiz, "Distributed MEMS true-time delay phase shifters and wide-band switches," IEEE Trans.Microw. Theory Tech., vol. 46, no. 11, pp. 1881-1890, Nov. 1998.

[23] G. McFeetors and M. Okoniewski, "Analog tunable microwave phase shifters using RF MEMS," in Proc. Int. Symp. Antenna Tech. Appl. Electromagn. and Int. Sci. Radio Union (URSI) Conf., 2004, pp. 29-32.

[24] A. R. Brown and G. M. Rebeiz, "Micromachined high-Q resonators, low-loss diplexers, and low phase-noise oscillators for a $28 \mathrm{GHz}$ frontend," in Proc. IEEE Radio Wireless Conf. (RAWCON99), 1999, pp. 247-253.

[25] E. Larique, P. Blondy, M. Chatras, D. Mercier, D. Cros, L. Basteres, and B. Guillon, "Tunable RF MEMS resonators and filters," Proc. SPIE-Int. Soc. Opt. Eng., vol. 4408, pp. 63-72, 2001.

[26] J.-P. Raskin, A. R. Brown, B. T. Khuri-Yakub, and G. M. Rebeiz, "A novel parametric-effect MEMS amplifier," J. Microelectromech. Syst., vol. 9, no. 4, pp. 528-537, Dec. 2000.

[27] H. T. Kim, S. Jung, K. Kang, J. H. Park, Y. K. Kim, and Y. Kwon, "Low-loss analog and digital micromachined impedance tuners at the Ka-band," IEEE Trans. Microw. Theory Tech., vol. 49, pp. 2394-2400, Dec. 2001.

[28] Y. Lu, L. P. B. Katehi, and D. Peroulis, "High-power MEMS varactors and impedance tuners for millimeter-wave applications," IEEE Trans. Microw. Theory Tech., vol. 53, no. 11, pp. 3672-3678, Nov. 2005
[29] A. Abbaspour-Tamijani, B. Schoenlinner, K. Sarabandi, and G. M. Rebeiz, "A new class of bandpass frequency selective structures," in Proc. IEEE Antenna Propagat. Int. Symp., 2003, vol. 2, pp. $817-820$, pt. 2.

[30] J. P. Gianvittorio, J. Zendejas, Y. Rahmat-Samii, and J. W. Judy, "MEMS enabled reconfigurable frequency selective surfaces: Design, simulation, fabrication, and measurement," in Proc. IEEE Antennas Propagat. Soc. Int. Symp., 2002, vol. 2, pp. 404-407, pt. 2.

[31] G. M. Rebeiz, W. G. Regehr, D. B. Rutledge, R. L. Savage, and N. C. Luhmann, Jr., "Submillimeter-wave antennas on thin membranes," Int. J. Infrared Millimeter Waves, vol. 8, no. 10, pp. 1249-1255, Oct. 1987.

[32] J.-C. Chiao, Y. Fu, I. M. Chio, M. DeLisio, and L.-Y. Lin, "MEMS reconfigurable Vee antenna," in Proc. IEEE MTT-S Int. Microw. Symp. Dig., 1999, vol. 4, pp. 1515-1518, pt. 4.

[33] C. L. Goldsmith, J. Randall, S. Esbelman, T. H. Lin, D. Denniston, S. Chen, and B. Norvell, "Characteristics of micromachined switches at microwave frequencies," in Proc. IEEE MTT-S Int. Microw. Symp. Dig., Jun. 1996, vol. 2, pp. 1141-1144.

[34] A. B. Yu, A. Q. Liu, Q. X. Zhang, A. Alphones, and H. M. Hosseini, "Micromachined DC contact capacitive switch on low-resistivity silicon substrate," Sens. Actuators A: Phys., vol. 127, no. 1, pp. 24-30, Feb. 2006.

[35] H. Lamb, "On electrical motions in a spherical conductor," Philos. Trans. London Roy. Soc. (II), vol. 174, pp. 519-549, 1883.

[36] Z. Wang, B. D. Jensen, L. L. W. Chow, J. L. Volakis, K. Saitou, and K. Kurabayashi, "Full-wave electromagnetic and thermal modeling for prediction of heat-dissipation-induced RF MEMS switch failure," $J$. Micromech. Microeng., vol. 16, pp. 157-164, 2006.

[37] X. Rottenberg, S. Brebels, W. De Raedt, B. Nauwelaers, and H. A. C. Tilmans, "RF-power: Driver for electrostatic RF-MEMS devices," $J$. Micromech. Microeng., vol. 14, pp. S43-S48, 2004.

[38] B. Ducarouge, E. Perret, F. Flourens, S. Melle, E. Ongareau, K. Grenier, A. Boukabache, V. Conedera, P. Pons, E. Perret, H. Aubert, and R. Plana, "Power capabilities of RF MEMS," in Proc. 24th Int. Conf. Microelectr. (MIEL 2004), May 2004, vol. 1, pp. 65-70.

[39] J. B. Rizk, E. Chaiban, and G. M. Rebiez, "Steady state thermal analysis and high-power reliability considerations of RF MEMS capacitive switches," in Proc. IEEE MTT-S Int. Microw. Symp. Dig., 2002, vol. 1, pp. 239-243.

[40] R. M. Reano, D. Peroulis, J. F. Whitaker, and L. P. B. Katehi, "Electro/ thermal measurements of RF MEMS capacitive switches," in Proc. IEEE MTT-S Int. Microw. Symp. Dig., 2003, vol. 3, pp. 1923-1926.

[41] J. C. Blair, C. R. Fuller, P. B. Ghate, and C. T. Haywood, "Electromigration-induced failures in, and microstructure and resistivity of, sputtered gold films," J. Appl. Phys., vol. 43, no. 2, pp. 307-311, Feb. 1972.

[42] J. Semancik, "4-wire measurement," Sensors, vol. 18, no. 5, pp. 44-50, 1991.

[43] C. W. Lewis, "Four-wire techniques minimize temperature measurement errors," InTech, vol. 42, pp. 40-43, 1995.

[44] L. L. W. Chow, Z. Wang, B. D. Jensen, K. Saitou, J. L. Volakis, and K. Kurabayashi, "Skin effects aggregated heating in RF MEMS suspended structures," presented at the IEEE MTT-S Int. Microw. Symp., Long Beach, CA, Jun. 12-17, 2005.

[45] B. D. Jensen, K. Saitou, J. L. Volakis, and K. Kurabayashi, "Fully integrated electrothermal multi-domain modeling of RF MEMS switches," IEEE Microw. Wireless Compon. Lett., vol. 13, no. 9, pp. 364-366, Sep. 2003.

[46] B. D. Jensen, Z. Wang, L. Chow, K. Saitou, K. Kurabayashi, and J. L. Volakis, "Integrated electrothermal modeling of RF MEMS switches for improved power handling capability," presented at the IEEE Topical Conf. Wireless Commun. Technol., Honolulu, HI, Oct. 15-17, 2003.

[47] Z. Wang, B. Jensen, J. Volakis, K. Saitou, and K. Kurabayashi, "A preconditioner for hybrid matrices arising in RF MEMS switch analysis," presented at the IEEE Int. Antenna Propagat. Symp., Monterey, CA, Jun. 20-26, 2004.

[48] Y. Kondoh, T. Takenaka, T. Hidaka, G. Tejima, Y. Kaneko, and M. Saitoh, "High-reliability, high-performance RF micromachined switch using liquid metal," J. Microelectromech. Syst., vol. 14, no. 2, pp. 214-220, Apr. 2005.

[49] P. Blondy, A. Crunteanu, C. Champeaux, A. Catherinot, P. Tristant, O. Vendier, J. L. Cazaux, and L. Marchand, "Dielectric less capacitive MEMS switches," in Proc. IEEE MTT-S Int. Microw. Symp. Dig., 2004, pp. 573-576.

[50] L. Guan, J. K. O. Sin, H. Liu, and Z. Xiong, "A fully integrated SOI RF MEMS technology for system-on-a-chip applications," IEEE Trans. Electron Devices, vol. 53, no. 1, pp. 167-172, Jan. 2006.

[51] N. Nishijima, J.-J. Hung, and G. M. Rebeiz, "A low-voltage high contact force RF-MEMS switch," in Proc. IEEE MTT-S Int. Microw. Symp. Dig., 2004, pp. 577-580. 
[52] M. Tang, A.-Q. Liu, A. Agarwal, Z.-S. Liu, and C. Lu, "A singlepole double-throw (SPDT) circuit using lateral metal-contact micromachined switches," Sens. Actuators A: Phys., vol. 121, pp. 187-196, 2005.

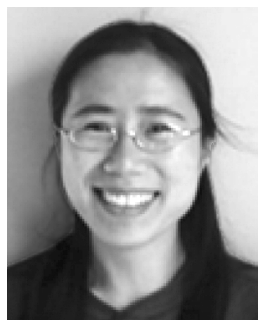

Linda L. W. Chow (S'02) is currently working towards the Ph.D. degree in mechanical engineering at University of Michigan, Ann Arbor.

She has studied RF MEMS switch design, fabrication process development, and thermal/contact reliability studies since Fall 2002. She was a Teaching Assistant for two semesters, and was chosen the Best Teaching Assistant. She has authored/coauthored about 20 conference/journal papers.

Miss Chow, in her master studies, developed an in situ moisture sensing chip for electronic packaging reliability testing, which was awarded the Best Student Paper in IEEE International Symposium on Electronic Materials and Packaging (EMAP2000).

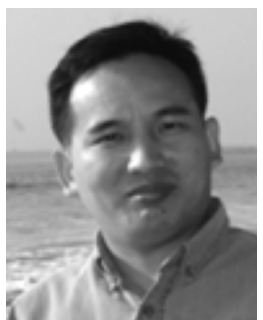

Zhongde Wang (M'04) received the M.Sc. degree in microwave/RF engineering from the University of Waterloo, Waterloo, ON, Canada, in 2002 and the $\mathrm{Ph} . \mathrm{D}$. degree in electrical engineering and computer science from the University of Michigan, Ann Arbor, in 2005

In January 2005, he joined Ansoft Corporation, San Jose, CA, as an Application Engineer. He has published over 20 papers in journals and conferences. His research focuses on computational electromagnetics, RF MEMS structure modeling, and antenna and microwave components optimization design.

Dr. Wang was awarded the Second Grade Prize for Science and Technologies Progress by the Chinese Electrical Ministry in 1996.

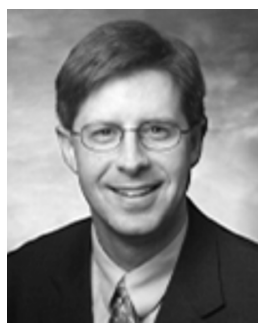

Brian D. Jensen received the B.S. and M.S. degrees in mechanical engineering from Brigham Young University, Provo, UT, in 1996 and 1998, respectively, and the M.S. degree in electrical engineering and the Ph.D. degree in mechanical engineering from the University of Michigan, Ann Arbor, in 2004.

Since January 2005, he has been an Assistant Professor in the Mechanical Engineering Department, Brigham Young University. He was previously a Postdoctoral Fellow at the University of Michigan. Before receiving the Ph.D. degree, he worked at Sandia National Laboratories as a Micromechanical Designer. He holds seven U.S. patents and has authored or coauthored over 35 technical papers.

Dr. Jensen received the National Science Foundation Graduate Research Fellowship as well as the National Defense Science and Engineering Graduate Fellowship.

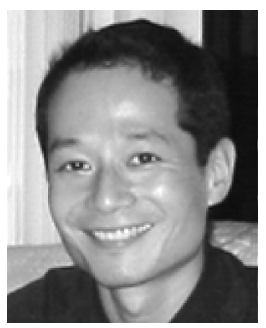

Kazuhiro Saitou (M'97) received the Ph.D. degree in mechanical engineering from the Massachusetts Institute of Technology (MIT), Cambridge, in 1996.

From 1997 to 2003, he was an Assistant Professor with the Department of Mechanical Engineering, University of Michigan, Ann Arbor, where he is currently an Associate Professor. His research interests include design automation and optimization, design for $\mathrm{X}$, where $\mathrm{X}=$ manufacture, assembly, robustness, environment, modeling, and optimization of MEMS, and evolutionary computation in

mechanical design.

Dr. Saitou is a Member of American Society of Mechanical Engineers (ASME), Society of Manufacturing Engineers, Association for Computing Machinery, and Sigma Xi. He is currently as an Associate Editor for IEEE TRANSACTIONS ON AUTOMATION SCIENCE AND ENGINEERING and an Editorial Board Member of the International Journal of CAD/CAM, and Genetic
Programming and Evolvable Machines. He was the recipient of the 1999 CAREER Award from the National Science Foundation (NSF), and of the Best Paper Award at the 5th International Symposium on Tools and Methods of Competitive Engineering in 2004.

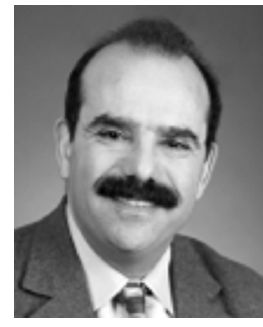

John L. Volakis (S'77-M'82-SM'89-F'96) was born on May 13, 1956 in Chios, Greece, and moved to the United States in 1973. He received the B.E. degree (summa cum laude) in 1978 from Youngstown State University, Youngstown, $\mathrm{OH}$, and the M.Sc. and the $\mathrm{Ph} . \mathrm{D}$. degrees from the Ohio State University (OSU), Columbus, in 1979 and 1982, respectively, all in electrical and computer engineering.

From 1982 to 1984, he was with Rockwell International, Aircraft Division (now Boeing Phantom Works), Lakewood, CA, and, during 1978-1982, he was a Graduate Research Associate at the ElectroScience Laboratory, OSU. Since January 2003, he has been the Roy and Lois Chope Chair Professor of Engineering at the OSU and also serves as the Director of the ElectroScience Laboratory. From 1984 to 2003, he was a Professor in the Electrical Engineering and Computer Science Department, the University of Michigan, Ann Arbor. He also served as the Director of the Radiation Laboratory, from 1998 to 2000. His primary research deals with computational methods, electromagnetic compatibility and interference, design of new RF materials, multiphysics engineering, and bioelectromagnetics. He published 220 articles in major refereed journals (nine of these have appeared in reprint volumes), more than 300 conference papers, and ten book chapters. In addition, he coauthored two books: Approximate Boundary Conditions in Electromagnetics (London, U.K.: Institution of Electrical Engineers, 1995) and Finite Element Method for Electromagnetics (Piscataway, NJ: IEEE Press, 1998). He graduated/mentored over $40 \mathrm{Ph} . \mathrm{D}$. and Postdoctoral student, and coauthored with them five best paper awards at conferences. He has also written two well-edited coursepacks on introductory and advanced numerical methods for electromagnetics, and has delivered short courses on numerical methods, antennas, and frequency selective surfaces.

Dr. Volakis received the University of Michigan College of Engineering Research Excellence Award, in 1998, and the University of Michigan, Department of Electrical Engineering and Computer Science Service Excellence Award, in 2001. He is listed by ISI HighlyCited.com among the top 250 most referenced authors $(2004,2005)$. He served as an Associate Editor of the IEEE TRANSACTIONS ON ANTENNAS AND PROPAGATION from 1988 to 1992, and as an Associate Editor of Radio Science, from 1994 to 1997. He chaired the 1993 IEEE Antennas and Propagation Society Symposium and Radio Science Meeting, and cochaired the same Symposium in 2003. He was a member of the AdCom for the IEEE Antennas and Propagation Society from 1995 to 1998 and served as the 2004 President of the IEEE Antennas and Propagation Society. $\mathrm{He}$ also serves as an Associate Editor for the Journal of Electromagnetic Waves and Applications, the IEEE ANTENNAS AND PROPAGATION SOCIETY MAGAZINE, and the International Union of Radio Science (URSI) Bulletin. He is a member of Commissions B and E of URSI.

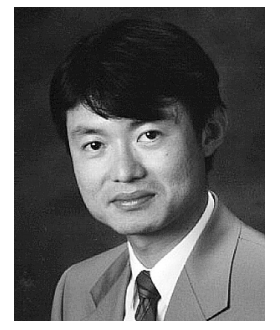

Katsuo Kurabayashi (M'00) received the B.S degree in precision engineering from the University of Tokyo, Tokyo, Japan, in 1992 and the M.S. and $\mathrm{Ph} . \mathrm{D}$. degrees in materials science and engineering with electrical engineering minor from Stanford University, Stanford, CA, in 1994 and 1998, respectively. His Ph.D. dissertation work focused on measurement and modeling of the thermal transport properties of electronic packaging and organic materials for integrated circuits under the contract with the Semiconductor Research Corporation (SRC).

He was a Research Associate with the Department of Mechanical Engineering at Stanford University for 12 months. In January 2000, he joined the faculty of the University of Michigan, Ann Arbor, where he is currently Associate Professor of Mechanical Engineering and Electrical Engineering and Computer Science. His group at the University of Michigan studies multiphysics modeling and characterization of RF MEMS, biomolecular motor hybrid NEMS/MEMS technology, and polymer-on-silicon strain-tunable photonic devices.

Dr. Kurabayashi received the SRC Best Paper Award, in 1998, the National Science Foundation (NSF) CAREER Award, in 2001, and the University of Michigan Robert Caddell Memorial Award, in 2004. 